\title{
O trabalho infantil e a educação de jovens e adultos na perspectiva de adultos trabalhadores
}

\section{Child work and youth and adult education in the perspective of adults workers}

\section{El trabajo infantil y la educación de jóvenes y adultos en la perspectiva de adultos trabajadores}

\author{
Aline Madia Mantouani" \\ Universidade Estadual Paulista "Júlio de Mesquita Filho" de Presidente Prudente, Egressa \\ Anderson dos Santos Carualho \\ Universidade de São Paulo, Doutorando em Ciências
}

Resumo: De um ponto de vista histórico, a educação da classe trabalhadora nem sempre foi considerada necessária e, por isso, nem sempre foi defendida nos textos legais. A discussão sobre esse assunto começou a avançar no âmbito legal em razão das mudanças ocorridas no mercado de trabalho, que passou a exigir do trabalhador a qualificação profissional necessária para a execução das mais diversas tarefas. Diante disso, o objetivo com este texto foi discutir sobre a Educação de Jovens e Adultos (EJA) enquanto política educacional dirigida à população jovem e adulta que pode ter tido a escolarização prejudicada pelo trabalho. É um estudo de cunho quanti-qualitativo, no qual participaram 131 adultos, de ambos os sexos, oriundos de duas instituições de ensino de um município de médio porte do Estado de São Paulo. Os dados foram obtidos a partir da utilização de um questionário internacional, submetido à análise no software SPSS e nos pressupostos da Análise de Conteúdo. Buscou-se analisar a EJA enquanto modalidade da Educação Básica destinada à população que não teve acesso à escola no tempo certo da infância e adolescência, bem como refletir acerca do trabalho infantil para além de um olhar generalista e universalista sobre o fenômeno. Os resultados apontam que, apesar do avanço legal, estrutural e organizacional, a EJA ainda não se constituiu uma

Doutora e Mestre em Educação pela Faculdade de Ciências e Tecnologia, Universidade Estadual Paulista "Júlio de Mesquita Filho", Campus de Presidente Prudente, SC.

2 Mestre em Educação Física pela Faculdade Metodista; Doutorando em Ciências no Programa Interunidades de Doutoramento em Enfermagem de Ribeirão Preto da Universidade de São Paulo (EERP-USP). 
política educacional efetiva para atender a classe trabalhadora e que é possível encontrar situações de trabalho infantil nos mais diversos espaços, tanto pelos aspectos sociais e econômicos que perpetuam as desigualdades quanto pela presença de características culturais e ideológicas que justificam sua existência.

Palavras-chave: Educação de Jovens e Adultos. Trabalho infantil. Adultos. Políticas educacionais.

Abstract: From a historical point of view, the education of the working class was not always considered necessary and, therefore, was not always defended in the legal texts. These discussions began to move forward in the legal framework due to changes in the labor market, which required the worker to have the necessary professional qualifications to perform the most diverse tasks. This text aims to discuss the Youth and Adult Education as an educational policy aimed at the young and adult population that may have had schooling hampered by work. It is a quantitative-qualitative study, in which 131 adults, of both sexes, came from two educational institutions of a medium-sized municipality in the State of São Paulo. The data were obtained from the use of an international questionnaire, submitted to analysis in the SPSS software and in the assumptions of Content Analysis. We sought to analyze the Youth and Adult Education as a modality of Basic Education aimed at the population that did not have access to the school in the right time of childhood and adolescence, as well as discussing child labor beyond a generalist and universalist view on the phenomenon. The results indicate that, despite the legal, structural and organizational progress of the Youth and Adult Education, it has not yet been established as an effective educational policy to serve the working class and that it is possible to find child labor situations in the most diverse spaces, both for the social and economic aspects that perpetuate the inequalities and the presence of cultural and ideological characteristics that justify its existence.

Keywords: Youth and Adult Education. Child work. Adults. Educational policies.

Resumen: Desde un punto de vista histórico, la educación de la clase trabajadora no siempre fue considerada necesaria y, por eso, no siempre fue defendida en los textos legales. Estas discusiones comenzaron a avanzar en el marco legal debido a los cambios ocurridos en el mercado de trabajo, que pasó a exigir del trabajador la cualificación profesional necesaria para la ejecución de las más diversas tareas. Este texto tiene por objetivo entender a Educación de Jóvenes 
y Adultos como política educativa dirigida a la población joven y adulta que puede haber tenido la escolarización perjudicada por el trabajo. Es un estudio cuantitativo cualitativo, en el que participaron 131 adultos, de ambos sexos, oriundos de dos instituciones de enseñanza de un municipio de mediano porte del Estado de São Paulo. Los datos fueron obtenidos a partir de la utilización de un cuestionario internacional, sometido al análisis en el software SPSS y en los supuestos del Análisis de Contenido. Se buscó analizar la Educación de Jóvenes y Adultos como una modalidad de la Educación Básica destinada a la población que no tuvo acceso a la escuela en el tiempo cierto de la infancia y adolescencia, así como discutir el trabajo infantil más allá de una mirada generalista y universalista sobre el fenómeno. Los resultados apuntan que, a pesar del avance legal, estructural y organizacional, la Educación de Jóvenes y Adultos aún no se constituyó como política educativa efectiva para atender a la clase trabajadora y que es posible encontrar situaciones de trabajo infantil en los más diversos espacios, tanto por los aspectos sociales y económicos que perpetuan las desigualdades en cuanto a la presencia de características culturales e ideológicas que justifican su existencia.

Palabras-clave: Educación de Jóvenes y Adultos. Trabajo infantil. Adultos. Políticas educativas.

\section{INTRODUÇÃO}

A partir da fala de adultos, estudantes em duas instituições que atendem na modalidade Educação de Jovens e Adultos (EJA) em um município de médio porte do Estado de São Paulo, buscamos a articulação entre dois fenômenos pouco explorados conjuntamente pela literatura, quais sejam, a EJA e o trabalho infantil. Para atender aos objetivos propostos, nossas discussões teóricas neste texto buscam compreender a EJA enquanto uma modalidade da Educação Básica destinada à população que não teve acesso à escola durante a infância e a adolescência, e refletir sobre o trabalho infantil para além de um olhar generalista e universalista sobre o fenômeno. Assim, adotouse um questionário internacional para a pesquisa de campo; os dados obtidos delineiam a amostra total participante, os impactos educacionais do trabalho 
precoce e os índices de valorização que os participantes atribuem à escola a que tiveram acesso.

Na tentativa de compreender a EJA e suas especificidades se torna necessário analisar o processo de conquista do direito à educação pela população adulta, conhecer quem são os sujeitos envolvidos, verificar a legislação que a norteia e o momento atual em que se encontra no País (DI PIERRO, 2010, 2015; DI PIERRO; HADDAD, 2015; HADDAD, SIQUEIRA, 2015). Dessa forma, concordamos com Morete (2010, p. 34), pois para "entendermos a presença ou ausência de uma política educacional voltada à educação de jovens e adultos, principalmente no que diz respeito ao tratamento dado pelas classes dominantes ao tema", torna-se necessário analisar o acesso da camada popular à educação e a legislação orientada para essa garantia.

Por esse viés crítico e investigativo também expomos sobre o trabalho infantil. Enquanto fenômeno social, cultural e econômico, percebemos que o trabalho infantil faz parte do desenvolvimento histórico da humanidade e está envolto a características ora positivas ora negativas quando falamos sobre os efeitos produzidos para o trabalhador. Dessa forma, partindo de uma análise histórica, elencamos alguns fatores que contribuíram para o seu desenvolvimento e fortalecimento em nossa sociedade, principalmente após a Revolução Industrial em meados do século XVIII, e apresentamos estudos que o caracterizam como algo negativo e prejudicial a quem o exerce, bem como autores que ressaltam os aspectos positivos que podem coexistir paralelamente a esses efeitos negativos sobre aqueles que trabalham.

A partir desse panorama inicial, ressaltamos que neste estudo se buscou uma articulação entre a EJA e o trabalho infantil na interface da vida adulta, tendo por objetivo discutir sobre a EJA enquanto política educacional dirigida à população jovem e adulta que pode ter tido a escolarização prejudicada pelo trabalho. 


\section{ASPECTOS TEÓRICOS SOBRE A EJA E O TRABALHO INFANTIL}

Em termos de definição, neste estudo entendemos a EJA enquanto modalidade da Educação Básica, nos níveis do Ensino Fundamental e do Ensino Médio, que se propõe a oferecer a oportunidade aos jovens e adultos de iniciarem e/ou continuarem os seus estudos, interrompidos por qualquer motivo durante o período considerado obrigatório legalmente, tornando-se um fator necessário de ação do poder público (MANTOVANI, 2017).

Da mesma forma, entendemos como trabalho infantil toda e qualquer atividade laboral que se executa antes da idade mínima prevista em lei (14 anos), sobretudo quando essa inserção prejudica e/ou inviabiliza o usufruto de direitos fundamentais garantidos por lei, como escolaridade, lazer, cultura, descanso, saúde e integridade (LIBÓRIO, 2009). Assim, definimos como inserção em trabalho infantil a presença de crianças e adolescentes em três setores da economia: doméstico (na própria casa ou na casa de terceiros), informal urbano (feiras, supermercados, oficinas, lanches, restaurantes, etc.) e rural (em fazendas próprias ou de outros proprietários) (MANTOVANI, 2017).

Apesar de as discussões sobre a universalização da EJA e a erradicação do trabalho infantil terem sido ampliadas nas últimas décadas, a educação da classe trabalhadora nem sempre foi considerada necessária na pasta de prioridades legais, e os índices de crianças e adolescentes envolvidos em situações laborais ainda são alarmantes, agravados por fatores como desigualdade social, desemprego e crise econômica.

Os debates na área da EJA começaram a tomar corpo a partir das mudanças ocorridas no mundo do trabalho, alavancadas, principalmente, pela Revolução Industrial e pelo processo de globalização. De acordo com Sampaio (2009, p. 15), "a história da EJA é uma história de tensões entre diferentes projetos de sociedade e diferentes ideias sobre as finalidades da educação." Sobre isso, Haddad (2007, p. 1997) afirma que:

Apesar de a Educação de Jovens e Adultos (EJA) no Brasil vir gradativamente sendo reconhecida como um direito 
para milhões de pessoas que não tiveram oportunidade de realizar sua escolaridade desde meados do século passado, esse direito só foi formalizado em lei, como dever de oferta obrigatória pelo Estado brasileiro, a partir da Constituição de 1988, e reafirmado pela Lei de Diretrizes e Bases de 1996. Mesmo assim, não se implantou nacionalmente uma política para EJA, nem se concretizou, como decorrência da conquista desse direito, um sistema nacional articulado de atendimento que permita que todos os cidadãos e cidadãs acima de 14 anos possam, pela escolarização, enfrentar os desafios de uma sociedade como a brasileira.

Para Costa (2013), a EJA sempre esteve articulada às reivindicações dos movimentos populares, quais sejam a garantia do acesso e permanência escolar dos jovens e adultos que não estudaram, ou que da escola foram excluídos, e a defesa da seguridade de uma educação pública de qualidade para todos. Assim, pensar a educação de jovens e adultos significa, sobretudo, "falar de jovens e adultos, trabalhadores-alunos, que formam e são formados ao longo da história, no seio das relações sociais de produção, marcadas pela exclusão e marginalização da maioria da população." (COSTA, 2013, p. 60).

No entanto, como já mencionado, essa preocupação começou a surgir no cenário educacional brasileiro, em termos de legislação e políticas públicas, apenas recentemente, após a promulgação da Constituição Federal de 1988 (COSTA, 2013; DI PIERRO, 2010, 2015; DI PIERRO, HADDAD, 2015; FARIAS, 2016; HADDAD, 2007; HADDAD, SIQUEIRA, 2015; MACHADO, 2011 ; SAMPAIO, 2009; SEPULVEDA, 2009).

De um ponto de vista legal, a educação pública e gratuita, garantida também aos jovens e adultos, foi assegurada pela primeira vez no Art. 208 da Constituição (BRASIL, 1988) nesses termos: "o dever do Estado com a educação será efetivado mediante a garantia de: I - ensino fundamental obrigatório e gratuito, inclusive para os que a ele não tiveram acesso na idade própria."

Posteriormente, em 1996, esse princípio se reafirma na Lei de Diretrizes e Bases da Educação Nacional (LDB) (BRASIL, 1996), pois em termos de direito a Lei prescreve que "a educação de jovens e adultos será destinada àqueles que não tiveram acesso ou continuidade de estudos no ensino fundamental e médio na idade própria." (Art. 37). A partir daí, a educação 
profissional foi contemplada dos Arts. 39 ao 42, com ênfase no entrelaçamento entre educação profissional e educação regular no Art. 40 (BRASIL, 1996). Diante desses apontamentos, Morete (2010, p. 51) afirma que:

\begin{abstract}
A Lei de Diretrizes e Bases da Educação de 1996 (LDB/96), na seção V, dedicada à educação básica de jovens e adultos, propõe dois artigos, nos quais é reafirmado o direito dos jovens e adultos trabalhadores ao ensino básico, ajustado às suas condições peculiares de estudo, bem como o dever do poder público em oferecê-lo gratuitamente na forma de cursos e exames supletivos. A novidade ficou por conta da diminuição da idade para candidatos aos exames supletivos, fixados em 15 anos para o ensino fundamental e 18 anos para o ensino médio, com a intenção de acelerar o fluxo e, assim, aumentar o número de concluintes do ensino fundamental. Com relação à legislação anterior, a LDB/96 termina com a distinção entre os subsistemas de ensino regular e supletivo, integrando a organização da educação de jovens e adultos a uma modalidade da educação básica, nas suas etapas fundamental e média.
\end{abstract}

Em seu estudo, Farias (2016) traça alguns apontamentos sobre os pressupostos da política educacional brasileira para a EJA e os avanços adquiridos após a LDB (BRASIL, 1996) reconhecê-la enquanto modalidade da Educação Básica. Para a autora, após se tornar uma política de Estado, a EJA passou a receber investimentos e incentivos do Governo brasileiro por ser uma alternativa para a diminuição do analfabetismo da população que não teve acesso ou possibilidade de estudar no tempo regular.

No entanto, de forma paradoxal, a autora registra as descontinuidades das políticas sociais voltadas à EJA, as quais reafirmam o descaso com o analfabetismo no Brasil, realidade que permanece em nossa sociedade até hoje. Considerando os atuais índices de pessoas que estão distantes de usufruir do seu direito à educação, conclui a autora que fica evidente que "há uma lacuna entre a legislação e sua implantação." (FARIAS, 2016, p. 73).

Os estudos de Di Pierro (2010, 2015), Di Pierro e Haddad (2015), Haddad e Siqueira (2015) e Machado (201 l) destacam que as iniciativas legais ainda não se constituíram enquanto política pública que envolve a população jovem e adulta, nem mesmo romperam com a visão que perpassa o imaginário 
social de que não é necessário se preocupar com a escolarização desses grupos etários, revelando a falta de consciência da importância de uma cultura letrada no País e da efetivação do princípio da educação como direito de todos:

\begin{abstract}
$\bigcirc$ analfabetismo entre a população de jovens e adultos no Brasil é persistente na sociedade brasileira, tem causas históricas e reflete problemas estruturais não superados. Apesar da sua persistência, e o analfabetismo ser reconhecido como uma violação do direito humano à educação, as diversas políticas públicas implementadas ao longo da história não conseguiram superar a questão, muito menos baixar os seus índices para padrões internacionais compatíveis com o nível de desenvolvimento do país. (HADDAD; SIQUEIRA, 2015, p. 89).
\end{abstract}

Ainda hoje percebemos na efetivação dos direitos garantidos por lei, dentre eles o de acesso e permanência na escola, resquícios do descompromisso com os sujeitos das classes pobres, principalmente quando são crianças e adolescentes trabalhadores, "impelidos à difícil relação trabalho versus escola, que resulta na perda educacional, sobretudo em termos de repetência, defasagem e evasão escolar, e também em prejuízos na futura inserção no trabalho e ascensão social." (ALBERTO et al., 201 l, p. 296).

Costa (2013) afirma que ainda é um grande desafio para o nosso País estabelecer políticas públicas que abarquem, de fato, o campo da EJA, com suas especificidades e características: horário de funcionamento, local, número de vagas, formação dos professores, organização das turmas e especificidade curricular. Farias (2016), Sampaio (2009) e Sepulveda (2009) destacam a presença, a ausência e as características dos cursos de formação de professores para lecionar nessa modalidade da Educação Básica, reforçando a ideia de que se faz necessário um plano de formação específico e efetivo para esses profissionais, com base nas políticas públicas já asseguradas.

Nessa mesma direção, Mantovani (2012) traz apontamentos sobre a organização das escolas, características e exigências desse alunado a partir da fala de profissionais da educação que atendem em instituições que oferecem essa modalidade de ensino, pois o que se nota é que, no formato em que está, a EJA não tem cumprido suas atribuições com essa parte da população, que, 
dentre tantos direitos negados (como saúde, moradia, lazer, cultura), também perde o direito a uma educação de qualidade.

De um ponto de vista crítico, podemos a acrescentar às exposições sobre a EJA apontamentos acerca das políticas sociais destinadas à educação profissional, conforme prescrições legais citadas anteriormente. Ramos e Stampa (2015) analisam a função de tais políticas vigentes no Brasil no contexto da atual conjuntura capitalista que permeia nossa sociedade. Os autores discutem como as transformações no mundo do trabalho têm redefinido as políticas dirigidas à classe trabalhadora e reforçado sobre ela a ideia de que todos têm as mesmas condições de trabalho e de acesso e permanência na escola - algo contraditório se olharmos para os índices de escolarização e desemprego da população menos favorecida de nosso País.

Asbahr (201 1 ) discute acerca da qualificação para o trabalho exigida atualmente em nossa sociedade à luz da relação entre educação e mercado de trabalho. Enquanto isso, Kuenzer (2006) confronta as políticas de educação profissional e as demandas da classe trabalhadora a partir das mudanças no mundo do trabalho e ressalta que tais políticas não surtiram o efeito anunciado e tornaram ainda mais precarizadas as ofertas educativas vigentes. Tendo por base estudos empreendidos no setor coureiro calçadista, a autora cita a precarização e o aumento da terceirização nesse setor, que passa a empregar a mão de obra de toda a família, inclusive das crianças e adolescentes que dela fazem parte, comprometendo seu acesso e permanência na escola.

Dessa forma, é necessário questionar a "qualidade da educação oferecida, os níveis de acesso e permanência disponíveis, o valor atribuído à escola e aquilo que ela representa para o estudante em geral e para aquele que trabalha e suas famílias, de forma particular" (MANTOVANI, 2012, p. 33), dado que na EJA a discussão sobre o mundo do trabalho foi relegada a segundo plano, embora esteja prevista nas normativas legais (DI PIERRO, 2010).

Sobre o mundo do trabalho, em especial do trabalho infantil, é a partir da Revolução Industrial, em meados do século XVIII, que as transformações e disparidades sociais começam a se acirrar, com reflexos diretos sobre as relações laborais. Kassouf (2007, p. 324) aponta que a utilização de crianças 
no mercado de trabalho teve um significativo agravamento no período da Revolução Industrial, pois "já em 1861 o censo da Inglaterra mostrava que quase $37 \%$ dos meninos e $21 \%$ das meninas de 10 a 14 anos trabalhavam."

Não apenas no contexto da Revolução Industrial, mas, para Stropasolas (2012), em todos os momentos históricos houve a exploração de mão de obra infantil em atividades econômicas produtivas por parte de empregadores, em grandes ou pequenas empresas, nos grandes centros urbanos ou em áreas rurais. De acordo com o autor, muitos benefícios foram adquiridos por meio da exploração daquelas famílias que se encontravam em situação de maior exclusão social, obrigadas a trabalhar, juntamente com seus filhos, em quaisquer lugares para lhes assegurar a sobrevivência.

Diante disso, as representações construídas e compartilhadas sobre o trabalho infantil, empreendidas pelos próprios sujeitos envolvidos ou a partir de uma inserção no contexto em que ocorre, são reveladoras da multiplicidade de sentidos que o cerca e nos levam a questionar as posições mais universalistas que pregam sobre os riscos e benefícios advindos dessa forma de trabalho. Ao olharmos para os estudos de Anyango-Kivuva (2006), Invernizzi e Tomé (2007), Sarmento (2005) e Woodhead (2004), verificamos que o trabalho infantil não deve ser interpretado de uma forma única e generalista.

A situação do adulto que trabalhou durante sua infância e/ou adolescência é discutida na literatura sob a perspectiva positiva e/ou negativa dos efeitos sobre a saúde, a escolarização (KUENZER, 2004, 2006; LIMA; ALMEIDA, 2010), os rendimentos (KASSOUF, 2000; KASSOUF; SANTOS, 2010) e o trabalho atual (CARVALHO, 2008; MANTOVANI, 2017).

Por essa perspectiva, entendemos que cada tipo de trabalho traz consigo riscos específicos e potenciais benefícios, principalmente quando se considera o ponto de vista do sujeito trabalhador. Há uma vasta literatura que apresenta tais posicionamentos, ora positivos, ora negativos sobre o trabalho, e se articula às demandas sociais. No entanto, ainda é escassa a discussão que busca a articulação entre o trabalho infantil e a EJA, enquanto política educacional destinada àqueles que podem ter tido sua escolarização prejudicada em decorrência da inserção precoce em trabalho, foco dessa discussão. 


\section{CAMINHOS METODOLÓGIICOS}

Este estudo está ancorado em uma abordagem quanti-qualitativa, cujo enfoque é compreender as nuances envoltas à EJA e ao trabalho infantil. De acordo com Fortin (2003), o método quantitativo é utilizado, normalmente, em um processo sistemático de coleta de dados observáveis e quantificáveis. Enquanto isso, Minayo (2010, p. 57) afirma que "o método qualitativo é o que se aplica ao estudo da história, das relações, das representações, das crenças, das percepções e das opiniões, produtos das interpretações que os humanos fazem a respeito de como vivem, constroem seus artefatos e a si mesmos, pensam e sentem."

Fizeram parte da pesquisa empírica 131 adultos, estudantes em duas escolas públicas estaduais de um município do Estado de São Paulo que atendem a população na modalidade EJA. Para a participação na pesquisa, todos os estudantes acima de 24 anos de idade, de ambas as instituições, foram convidados, configurando uma amostragem intencional e por adesão voluntária.

As instituições selecionadas para compor a pesquisa fazem parte da mesma Diretoria Regional de Ensino e configuram-se enquanto Escola Estadual (EE) e Centro Estadual de educação de Jovens e Adultos (CEEJA). A primeira delas localiza-se em uma área central da cidade e é composta por turmas de EJA nos Ensinos Fundamental e Médio durante o período noturno. Por sua vez, a segunda está localizada em um bairro afastado do centro e atende os estudantes em horários flexíveis e com atendimento individualizado.

Foi utilizado um questionário baseado nos estudos internacionais de Ungar e Liebenberg (2013). O instrumento é composto por três partes, complementares entre si, e encaminha para o levantamento dos dados sociodemográficos, das implicações do trabalho precoce sobre a escolarização, do envolvimento em situações de trabalho infantil e dos indicadores de resiliência. Assim, cabe ressaltar que buscamos neste estudo a caracterização da amostra participante (sexo e idade), a análise dos impactos educacionais do trabalho precoce exercido (idade que parou de estudar, série e motivos 
para sair da escola) e a compreensão dos índices de valorização da escola, deixando a discussão sobre os indicadores de resiliência para outro momento.

\section{RESULTADOS E DISCUSSÃO}

Participaram da pesquisa sujeitos adultos, 131 no total, sendo 53,4\% mulheres e 46,6\% homens. Na EE contamos com a participação de 45 estudantes (34,4\% da amostra), enquanto no CEEJA foram 86, correspondendo a 65,6\% da amostra. Na Tabela 1 apresentam-se essas informações de forma clara:

Tabela 1 - Frequências absoluta e relativa do sexo e local de estudo dos participantes

\begin{tabular}{lrr}
\hline Variáveis & Frequência Absoluta $(\mathbf{n}=\mathbf{1 3 1})$ & Frequência Relativa (\%) \\
\hline Sexo & & \\
Mulher & 70 & 53,4 \\
Homem & 61 & 46,6 \\
Local de estudo & & \\
EE & 45 & 34,4 \\
CEEJA & 86 & 65,6 \\
\hline
\end{tabular}

Fonte: os autores.

Para Blum (2012) e Souza (2012), dados como esses, que revelam maior participação feminina em cursos para completar a escolarização básica garantida em lei, vão ao encontro de uma tendência histórica que ainda persiste em nossa sociedade de que as mulheres sempre foram as menos escolarizadas, obrigadas a atravessarem questões internas à escola (como fracasso, trajetória malsucedida, reprovação e abandono) e extraescolares (como pobreza, ingresso no mercado de trabalho, impedimento dos pais ou maridos e necessidades familiares) para estudarem.

Quando olhamos para a faixa etária da amostra reiteramos essa afirmação e percebemos que as faixas etárias mais elevadas são aquelas menos escolarizadas, principalmente para as mulheres: de 21 a 72 anos para as 
mulheres (média 38,24; desvio padrão 9,86) e de 21 a 60 anos para os homens (média 39,59; desvio padrão 10,53).

Por outro lado, também citamos o estudo de Haddad (2007) sobre o processo de juvenilização do Ensino Supletivo e de outros cursos de EJA na América Latina. De acordo com o autor, pessoas cada vez mais novas têm sido encaminhadas para turmas de EJA, antes indicadas para indivíduos adultos e idosos que não tiveram acesso à escolarização na idade certa; dentre os principais motivos elencados está o fato de essas pessoas sentirem-se excluídas da escola, seguido dos casos que envolvem a necessidade de trabalhar para ajudar na renda familiar.

Tabela 2 - Frequências absoluta e relativa da faixa etária e da série escolar dos participantes ao pararem de estudar

\begin{tabular}{|c|c|c|}
\hline Variáveis & Frequência Absoluta $(n=131)$ & Frequência Relativa (\%) \\
\hline \multicolumn{3}{|l|}{ Faixa etária } \\
\hline 7 a 10 anos & 22 & 16,8 \\
\hline 11 a 14 anos & 37 & 28,2 \\
\hline 15 a 17 anos & 32 & 24,4 \\
\hline Acima de 18 anos & 18 & 13,7 \\
\hline Não informado & 22 & 16,8 \\
\hline \multicolumn{3}{|l|}{ Série escolar } \\
\hline Não frequentei & 01 & 0,8 \\
\hline $1^{a}$ a $4^{a}$ série & 30 & 22,9 \\
\hline $5^{a}$ a $8^{a}$ série & 62 & 47,3 \\
\hline Ensino Médio & 32 & 24,4 \\
\hline Não informado & 06 & 4,6 \\
\hline
\end{tabular}

A Tabela 2 apresenta informações acerca da faixa etária e da série escolar em que se encontravam esses participantes ao deixarem a escola e contribui para a análise dos impactos educacionais advindos pelo trabalho infantil desenvolvido a que nos propomos. Ressalta-se que, posteriormente, discutiremos os motivos que desencadearam esse afastamento dos bancos escolares. 
Notamos que a maioria dos participantes deixou a escola quando tinha entre 11 e 14 anos de idade (28,2\%), seguidos daqueles com idades de 15 a 17 anos $(24,4 \%)$ e dos que se encontravam abaixo dos 10 anos de idade (16,8\%). Sobre a série em que parou de estudar, grande parte da amostra deixou a escola no Ensino Fundamental II (5 a $8^{a}$ série) (47,3\% dos casos), seguida de 24,4\% no Ensino Médio; 22,9\% no Ensino Fundamental I ( $1^{\mathrm{a}}$ a $4^{\mathrm{a}}$ série) e apenas $0,8 \%$ não frequentou a escola.

Dessa forma, os dados dessa Tabela (faixa etária e série em que parou de estudar) indicam que esses respondentes deixaram a escola durante o período considerado como educação básica obrigatória atualmente, que engloba os sujeitos dos quatro aos 17 anos de idade, conforme prescrições do Art. 208, Inciso I, da Constituição Federal, "Educação Básica obrigatória e gratuita dos 4 aos 17 anos de idade, assegurada inclusive sua oferta gratuita para todos os que a ela não tiveram acesso na idade própria." (BRASIL, 2009).

Quanto à faixa etária, notamos que os participantes deixaram a escola e começaram a trabalhar no período ( 11 aos 14 anos) de maiores registros de crianças e adolescentes em situações de trabalho (ALBERTO et al., 201 l; LIBÓRIO, 2009). De acordo com os autores, é a partir dos nove anos de idade que aumenta a ocupação de crianças em regiões metropolitanas, urbanas e rurais e depois dos 10 anos que algumas delas iniciam a busca por trabalho/ emprego nas referidas áreas.

Os participantes também puderam elencar os motivos que os afastaram da escola, e para 56,5\% foi o trabalho o principal deles. Classificados como "outros", em 27,5\% dos casos surgiram como motivos para sair da escola: acidente, alcoolismo do pai, casamento, cirurgia, dificuldade em entender os professores, doença, falecimento da mãe/dos pais, falta de incentivo dos pais, falta de permissão do pai para o estudo, gravidez, medo da violência, nascimento de filhos/filhos pequenos, seções de fisioterapia e teatro.

Seguindo esses índices ainda apareceram falta de interesse (16,8\%), morar na área rural (16\%), morar longe da escola (14,5\%) e mudança de bairro, escola ou cidade (11,5\%). Obtiveram porcentagens mais baixas a falta de dinheiro $(7,6 \%)$ e a qualidade da escola $(0,8 \%)$. $\bigcirc$ nível de formação 
dos professores não foi um motivo que contribuiu para que os participantes parassem os estudos durante sua infância ou adolescência, embora tenham registrado como "outros motivos" a dificuldade em entendê-los.

Os dados nos mostram que o trabalho contribuiu significativamente para a saída dos participantes da escola na época de sua infância ou adolescência (ALVES-MAZZOTTI, 1998; KASSOUF, 2000). Todavia, um conjunto de fatores, também extraescolares (como falta de interesse, morar na área rural/longe da escola, mudança e falta de dinheiro), fez com que a saída da escola ultrapassasse os limites legais vigentes, que prescrevem sobre a obrigatoriedade do acesso e da permanência na escola de todos os cidadãos em nosso País dos quatro aos 17 anos de idade.

Dessa forma, vemos que o trabalho infantil foi a principal causa elencada por esses adultos para a saída da escola, porém não foi a única. É preciso questionar a qualidade da educação oferecida, os caminhos para o acesso e permanência disponíveis e as formas de avaliação do desempenho do aluno nos estudos. Quando olhamos para o público da EJA, alunostrabalhadores, de uma forma específica, acrescentam-se a esses pontos as necessidades financeiras da família, o valor atribuído à escola, aquilo que ela representa para o estudante e quais são os interesses e necessidades dessa população, contemplados ou não nessa modalidade de ensino (KASSOUF, 2007; MANTOVANI, 2017; PESSOA; LIBÓRIO; VIOTTO FILHO, 2015).

Nas falas desses participantes é possível perceber que eles entendem que é por meio dos estudos que poderão melhorar sua situação de vida atual e que voltaram a estudar em razão das exigências do mesmo mercado de trabalho que os impediu de ir à escola na idade certa de suas vidas. Em contrapartida, além de o trabalho ser considerado motivo para a saída precoce da escola, também é visto como promotor de aprendizagem, cultura e valores, e há a crença de que por meio do estudo se adquire o conhecimento necessário para a conquista de empregos futuros, com melhores salários e a garantia de melhores condições de vida para si e para a família (MANTOVANI, 2017; SARTORI, 2006; SOUSA; ALBERTO, 2008). 


\section{CONCLUSÃO}

As informações levantadas neste estudo permitiram análises que tinham como foco discutir sobre a EJA na interface com o trabalho infantil a partir da fala de adultos. Ao entendermos a EJA enquanto uma política educacional voltada para a população que não teve acesso à escola na idade certa de suas vidas, temos consciência de que o processo de escolarização foi prejudicado, entre outros motivos, pelo trabalho.

A conquista do direito à educação pela população jovem e adulta, ainda que prescrita nos textos legais, enfrenta uma dura luta em busca de sua efetiva implementação, processo esse fortemente marcado por reivindicações da sociedade civil e descontinuidades governamentais. Da mesma forma, o trabalho infantil deve ser analisado enquanto um fenômeno multidimensional e problematizado a partir de elementos paradoxais, uma vez que pode estar associado a interpretações ora positivas ora negativas por parte dos sujeitos trabalhadores, além dos sentidos pessoais que estes atribuem ao trabalho, reflexos de fatores culturais, ideológicos e sociais advindos de seus contextos.

Devemos considerar, assim, que a EJA ainda não se constituiu eficazmente para atender a população adulta e que o trabalho infantil é gerado por uma sociedade excludente e desigual, que encaminha crianças e adolescentes a tais situações, em detrimento de um olhar que valorize outras áreas do desenvolvimento humano, como a educação, a saúde, o lazer e o descanso.

A necessidade financeira, aliada a aspectos internos e externos à escola, apareceu nos discursos dos participantes como motivo para a saída da escola e a inserção no mercado de trabalho. Sabemos que os fatores econômicos podem acirrar as desigualdades sociais e perpetuar ciclos intergeracionais de trabalho infantil entre as famílias; porém, alguns aspectos culturais, valorativos e ideológicos favorecem e legitimam sua ocorrência, principalmente pelo fato de 0 trabalho ser visto como favorecedor de responsabilidade, autoestima positiva, socialização e por afastar as crianças e adolescentes da marginalidade (MANTOVANI, 2017). 
Reconhecemos, nesta exposição, que os participantes tiveram sua escolarização prejudicada pelo trabalho e por fatores alheios a ele e buscam na EJA melhores posições sociais; da mesma forma acreditam que o trabalho, que no passado contribuiu para o afastamento da escola, é aquele que impulsiona para a volta/continuidade dos estudos na vida adulta.

Assim, esses pressupostos nos levam a entender que, se não existem programas sociais que deem conta das necessidades das famílias, se as políticas públicas não contemplam toda a população em situação de risco, se o acesso e a permanência na escola ainda não são para todos e se as desigualdades sociais não param de assolar as pessoas, será com o trabalho (inclusive o infantil) que a população menos favorecida resolverá essas questões. Ou seja, será o trabalho (infantil) que suprirá essas demandas e contribuir para o desenvolvimento dos indivíduos, apesar das adversidades impostas.

\section{REFERÊNCIAS}

ALBERTO, M. de F. P. et al. $\bigcirc$ trabalho infantil doméstico e o processo de escolarização. Psicologia \& Sociedade, Belo Horizonte, v. 23, n. 2, p. 293-320, 2011 .

ALVES-MAZZOTTI, A. J. Trabalho infanto-juvenil: representações de meninos trabalhadores, seus pais, professores e empregadores. In: MOREIRA, A. S. P.; OLIVEIRA, D. C. (Org.). Estudos Interdisciplinares de Representação Social. Goiânia: AB, 1998. p. 285-301.

ANYANGO-KIVUVA, L. The forgotten poor: problematizing policies of children 's work and schooling in Kenya. 2006. Tese (Doutorado em Filosofia)Faculty of School of Education, University of Pittsburg, Pittsburg, 2006.

ASBAHR, F. da S. F. "Por que aprender isso, professora?" Sentido pessoal e atividade de estudo na Psicologia Histórico-Cultural. 201 1. Tese (Doutorado em Psicologia)-Universidade de São Paulo, São Paulo, 2011.

\section{BLUM, D. A. O Programa de Erradicação do Trabalho Infantil (PETI) no} município de Ponta Grossa - PR: uma avaliação sobre a política pública de enfrentamento ao trabalho infantil (2010). 2012. Dissertação (Mestrado em Ciências Sociais Aplicadas)-Universidade Estadual de Ponta Grossa, Ponta Grossa, 2012. 
BRASIL. Constituição. República Federativa do Brasil de 1988. Brasília, DF: Senado Federal, 05 out. 1988.

BRASIL. EC n. 59, de 11 de novembro de 2009. Acrescenta $\S 3^{\circ}$ ao art. 76 do Ato das Disposições Constitucionais Transitórias para reduzir, anualmente, a partir do exercício de 2009, o percentual da Desvinculação das Receitas da União incidente sobre os recursos destinados à manutenção e desenvolvimento do ensino de que trata o art. 212 da Constituição Federal, [...] com a inserção neste dispositivo de inciso VI. Diário Oficial da União, Brasília, DF, 11 nov. 2009.

BRASIL. Lei n. 9.394, de 20 de dezembro de 1996. Estabelece as diretrizes e bases da educação nacional. Diário Oficial da União, Brasília, DF, 20 dez. 1996.

CARVALHO, I. M. M. de. O trabalho infantil no Brasil Contemporâneo. Caderno CRH, Salvador, v. 21, n. 54, p. 551-569, set./dez. 2008.

COSTA, C. G. Desafios da EJA em face das transformações do trabalho. Revista Lugares de Educação, Bananeiras, v. 3, n. 6, p. 90-103, jul./dez. 2013.

DI PIERRO, M. C. A Educação de Jovens e Adultos no Plano Nacional de Educação: avaliação, desafios e perspectivas. Educação \& Sociedade, Campinas, v. 31, n. 112, p. 939-959, jul./set. 2010.

DI PIERRO, M. C.; HADDAD, S. Transformações nas políticas de Educação de Jovens e Adultos no Brasil no início do Terceiro Milênio: uma análise das agendas nacional e internacional. Cadernos Cedes, Campinas, v. 35, n. 96, p. 197-217, maio/ago. 2015.

DI PIERRO, M. C. O impacto da inclusão da Educação de Jovens e Adultos no Fundo de Manutenção e Desenvolvimento da Educação Básica: um estudo em municípios paulistas. Em Aberto, Brasília, DF, v. 28, n. 93, p. 1 19-130, jan./ jun. 2015.

FARIAS, A. F. O processo de formação inicial de professores dos anos iniciais da EJA: uma análise do curso de Pedagogia de universidades estaduais de São Paulo. 2016. Dissertação (Mestrado em Educação)-Universidade Estadual Paulista, Presidente Prudente, 2016.

FORTIN, M. F. O processo de investigação: da concepção à realização. 3. ed. Loures: Lusociência, 2003. 
HADDAD, S. A ação de governos locais na Educação de Jovens e Adultos. Revista Brasileira de Educação, Rio de Janeiro, v. 12, n. 35, p. 197-21 1, maio/ ago. 2007.

HADDAD, S.; SIQUEIRA, F. Analfabetismo entre jovens e adultos no Brasil. Revista Brasileira de Alfabetização, Vitória, v. 1, n. 2, p. 88-1 10, jul./dez. 2015.

INVERNIZZI, A.; TOMÉ, S. O trabalho dos adolescentes no Algarve: um estudo sobre as suas motivações, organização familiar e práticas de socialização.

Análise Social, Lisboa, v. 42, n. 184, p. 875-898, 2007.

KASSOUF, A. L. $\bigcirc$ efeito do trabalho infantil para o rendimento e a saúde dos adultos. In: ENCONTRO BRASILEIRO DE ECONOMETRIA, 22., Campinas, 2000. Anais... Campinas: CEPEA/EsalQ/USP, 2000. Disponível em: <https:// www.cepea.esalq.usp.br/br/documentos/texto/o-efeito-do-trabalho-infantil-para-os-rendimentos-e-a-saude-dos-adultos-a-artigo-apresentado-no-xxii-encontro-brasileiro-de-econometria-2000.aspx>. Acesso em: 15 maio 2016.

KASSOUF, A. L. O que conhecemos sobre o trabalho infantil? Nova Economia, Minas Gerais, v. 17, n. 2, p. 323-350, 2007.

KASSOUF, A. L.; SANTOS, M. J. dos. Trabalho infantil no meio rural brasileiro: evidências sobre o "Paradoxo da Riqueza". Economia Aplicada, Ribeirão Preto, v. 14, n. 3, p. 339-353, 2010.

KUENZER, A. Z. A Educação Profissional nos anos 2000: a dimensão subordinada das políticas de inclusão. Educação \& Sociedade, Campinas, v. 27, n. 96, p. 877-910, out. 2006. Edição especial.

KUENZER, A. Z. Sob a reestruturação produtiva, enfermeiros, professores e montadores de automóveis se encontram no sofrimento do trabalho. Trabalho, Educação e Saúde, Rio de Janeiro, v. 2, p. 107-1 19, 2004.

LIBÓRIO, R. M. C. Crianças e adolescentes em situação de risco: dimensões do trabalho infantil nos municípios de Presidente Prudente, Belo Horizonte e Porto Alegre. 2009. [No prelo].

LIMA, A. C. de; ALMEIDA, A. M. Permanências e mutações na definição intergeracional do trabalho infantil. Educação \& Sociedade, Campinas, v. 31, n. 111, p. 347-369, abr./jun. 2010.

MACHADO, M. M. A Educação de Jovens e Adultos no século XXI: da alfabetização ao ensino profissional. Inter-Ação, Goiânia, v. 36, n. 2, p. 393-412, jul./ dez. 2011. 
MANTOVANI, A. M. Trabalho Infantil e desenvolvimento na perspectiva de profissionais da educação e famílias. 2012. Dissertação (Mestrado em Educação)-Universidade Estadual Paulista, Presidente Prudente, 2012.

MANTOVANI, A. M. Trabalho infantil e resiliência na vida de estudantes da EJA. 2017. Tese (Doutorado em Educação)-Universidade Estadual Paulista, Presidente Prudente, 2017.

MORETE, R. de C. B. S. O Centro Estadual de Educação de Jovens e Adultos de Presidente Prudente (CEEJA-PP) significa realmente espaço formativo? 2010. Dissertação (Mestrado em Educação)-Universidade Estadual Paulista, Presidente Prudente, 2010.

MYNAIO, M. C. de S. (Org.). Pesquisa Social: teoria, método e criatividade. 29. ed. Petrópolis: Vozes, 2010.

PESSOA, A. S. G.; LIBÓRIO, R. M.; VIOTTO FILHO, I. A. T. Trabalho e educação no contexto de adolescentes brasileiros: reflexões sobre retóricas de erradicação e políticas sociais. Nuances: estudos sobre educação, Presidente Prudente, v. 26, n. 1, p. 66-79, jan./abr. 2015.

RAMOS, M. S.; STAMPA, I. T. Políticas de Educação Profissional: naturalização das expressões da questão social? Argumentum, Vitória, v. 7, n. 2, p. 74-88, jul./dez. 2015.

SAMPAIO, M. N. Educação de Jovens e Adultos: uma história de complexidade e tensões. Práxis Educacional, Vitória da Conquista, v. 5, n. 7, p. 13-27, jul./dez. 2009.

SARMENTO, M. J. Trabalho infantil em Portugal: controvérsias e realidades. In: VIEIRA, C. et al. (Org.). Ensaios sobre o Comportamento Humano. Coimbra: Almedina, 2005. p. 95-1 16.

SARTORI, E. Trabalho infantil em Franca: um laboratório das lutas sociais em defesa da criança e do adolescente. Cadernos Pagu, Campinas, v. 26, p. 253-278, jan./jun. 2006.

SEPULVEDA, F. G. B. Educação de Jovens e Adultos: análise da política e da prática de formação de educadores no Programa Brasil Alfabetizado. 2009. Tese (Doutorado em Educação)-Pontifícia Universidade Católica de São Paulo, São Paulo, 2009.

SOUSA, O. M. C. G. de; ALBERTO, M. de F. P. Trabalho precoce e processo de escolarização de crianças e adolescentes. Psicologia em Estudo, Maringá, v. 13, n. 4, p. 713-722, out./dez. 2008. 
SOUZA, M. E. C. de. Mais tempo na escola, menos tempo no trabalho: articulação entre políticas sociais e educacionais no combate ao trabalho infantil. 2012. Tese (Doutorado em Educação)_Universidade Federal da Paraíba, João Pessoa, 2012.

STROPASOLAS, V. L. Trabalho infantil no campo: do problema social ao objeto sociológico. Revista Latino-Americana de Estudos do Trabalho, v. 17, n. 27, p. 249-286, 2012.

UNGAR, M.; LIEBENBERG, L. The Resilience Research Centre Adult Resilience Measure (RRC-ARM). User's manual: Research, 2013.

WOODHEAD, M. Psychosocial impacts of child work: a framework for research, monitoring and intervention. The International Journal of Children`s Rights, v. 12, p. 321-377, 2004.

Recebido em 31 de outubro de 2017 Aceito em 30 de julho de 2018

Endereços para correspondência: Avenida Rui Barbosa, 213, Centro, 19560000, Indiana, São Paulo, Brasil; alinemadia@hotmail.com 
